\title{
PENGARUH MODAL KERJA TERHADAP RENTABILITAS PADA PT. BUKIT AGUNG SEHATI PALEMBANG
}

\author{
AGUS SALIM \\ Dosen Tetap Fakultas Ekonomi Universitas Palembang
}

\begin{abstract}
ABSTRAK
Penelitian ini menguji Pengaruh Pengaruh Modal Kerja Terhadap Rentabilitas Pada PT. Bukit Agung Sehati Palembang. Tujuan dari penelitian ini adalah Untuk mengetahui modal kerja mempunyai pengaruh terhadap rentabilitas pada PT. Bukit Agung Sehati Palembang selama periode 2015-2019. Metode Penelitian dengan menggunakan Obyek Penelitian yang dilakukan di PT. Bukit Agung Sehati Palembang yang beralamat di Jalan Padat Karya Rt.4 No.18 Kelurahan Talang Buluh Kecamatan Talang Kelapa Kabupaten Banyuasin. Di mana Ruang lingkup penelitian adalah Modal Kerja terhadap kinerja keuangan di PT. Bukit Agung Sehati Palembang, laporan keuangan yaitu Neraca dan Rugi- laba. Dari hasil perhitungan maka dapat dibentuk persamaan regresi yaitu : $\mathrm{Y}=0,315+0,019 \mathrm{X}$

Hasil yang didapat dari analisis regresi sederhanan dengan mengunakan alat SPSS versi 22 menunjukkan bahwa ada pengaruh dari Modal Kerja Terhadap Rentabilitas Pada PT. Bukit Agung Sehati Palembang.
\end{abstract}

\section{Kata Kunci: Modal Kerja, Rentabilitas}

\section{PENDAHULUAN}

\subsection{Latar Belakang}

Dalam menghadapi krisis finansial yang terjadi sekarang ini, sebuah perusahaan ataupun lembaga usaha baik milik pemerintah maupun swasta dituntut untuk lebih memaksimalkan kinerjanya dalam berbagai hal terutama dalam hal memperoleh laba karena pada umumnya suatu perusahaan didirikan dengan tujuan untuk memperoleh laba atau keuntungan yang semaksimal mungkin demi menjamin kelangsungan hidup perusahaan tersebut agar tetap bertahan sampai masa yang akan datang. Untuk mencapai tujuan tersebut, sangat diperlukan adanya kerjasama yang baik antara manajer bersama para karyawannya dalam memanfaatkan dan mengelola sumber-sumber dana yang ada dalam lingkungan perusahaan tersebut secara efisien dan efektif.

Besarnya jumlah laba yang dicapai oleh suatu perusahaan bukanlah merupakan suatu jaminan atau ukuran bahwa suatu perusahaan tersebut telah memanfaatkan sumber dana yang ada secara efektif, melainkan masih ada faktor lain yang ikut mempengaruhi. Faktor lain tersebut adalah perbandingan antara laba yang diperoleh dengan jumlah seluiruh modal yang digunakan untuk meghasilkan laba tersebut yang dinamakan dengan rentabilitas. Dengan demikian, yang harus diperhatikan oleh perusahaan adalah tidak hanya bagaimana usaha untuk memperbesar laba, tetapi yang lebih penting adalah usaha untuk mempertinggi rentabilitasnya. Oleh sebab itu, perusahaan lebih berusaha untuk mendapatkan titik rentabilitas maksimal daripada laba maksimal.

Dalam menjalankan perusahaan, manajer perusahaan tidak akan terlepas dari permodalan perusahaan yaitu pemenuhan modal kerja maupun investasi. Apabila perusahaan telah mencapai posisi tertentu dapat melakukan ekspansi atau perluasan usaha. Dalam melakukan ekspansi, suatu perusahaan tidak akan terlepas dari kebutuhan akan modal. Pemenuhan kebutuhan modal tersebut dapat dilakukan dengan berbagai cara, antara 
lain dengan modal sendiri yang terdiri dari saldo laba, modal dari pemegang saham dan dari sumber lainnya yaitu modal pinjaman atau dapat pula diperoleh dengan mengkombinasikan keduanya.

Modal kerja merupakan masalah pokok dan topik penting yang sering kali dihadapi oleh perusahaan, karena hampir semua perhatian untuk mengelola modal kerja dan aktiva lancar yang merupakan bagian yang cukup besar dari aktiva. Modal kerja dibutuhkan oleh setiap perusahaan untuk membelanjai operasinya sehari-hari, misalnya : untuk memberikan persekot pembelian bahan mentah, membiayai upah gaji pegawai, dan lain-lain, dimana uang atau dana yang dikeluarkan tersebut diharapkan dapat kembali lagi masuk dalam perusahaan dalam waktu singkat melalui hasil penjualan produksinya. Oleh karena itu, perusahaan di tuntut untuk $\mathrm{s}$ elalu meningkatkan efisiensi kerjanya sehingga dicapai tujuan yang diharapkan oleh perusahaan yaitu mencapai laba yang optimal. Pengelolaan modal kerja merupakan hal yang sangat penting dalam perusahaan, karena meliputi pengambilan keputusan mengenai jumlah dan komposisi aktiva lancar dan bagaimana membiayai aktiva ini.

PT. Bukit Agung Sehati Palembang merupakan usaha yang bergerak di bidang industri konstruksi, industri pabrikasi, jasa penyewaan, jasa keagenan, investasi, agro industri, Engineering Procurement dan Contruction (EPC) perdagangan, pengelolaan kawasan layanan jasa peningkatan kemampuan dibidang konstruksi, teknologi informasi , kepariwisataan, perhotelan, jasa engineering dan perencanaan pengembang untuk menghasilkan barang atau jasa yang bermutu tinggi dan berdaya saing kuat..Kegiatan usaha yang saat ini dilakukan addalah jasa Konstruksi,Realti (Pengembang), properti dan investasi di bidang infrastruktur dan Energi. PT. Bukit Agung Sehati Palembang sebagai perusahaan yang bergerak di bidang industri konstruksi dan realti (pengembang) membutuhkan metode pendanaan dan pengelolaan dana keuangan yang efektif. Pengelolaan dana yang dimaksud adalah pengelolaan yang wajib mempertimbangkan tingkat keamanan, tingkat hasil, dan tingkat rentabilitas yang sesuai dengan kewajiban yang harus dipenuhi. Analisis modal kerja dan likuiditas terhadap kinerja keuangan pada PT. Bukit Agung Sehati Palembang bertujuan untuk mengetahui bagaimana perusahaan tersebut menggunakan modal yang ada serta tingkat likuiditas yang dicapai sehingga berpengaruh terhadap laba yang diperoleh .

Berdasarkan fenomena di atas, penulis mencoba untuk meneliti sejauh mana modal kerja berpengaruh terhadap rentabilitas. Sebagai bahan perbandingan, penelitian ini merujuk pada penelitian terdahulu yang dilakukan oleh:

- Ati Susanti (2016), dengan judul "Pengaruh Perputaran Modal Kerja Terhadap Rentabilitas pada PT. Jaya Maju bersama”. Melalui penelitiannya diperoleh hasil bahwa perputaran modal kerja tidak berpengaruh terhadap rentabilitas.

- Rizal Rizaludin (2017), dengan judul "Pengaruh Modal Kerja Terhadap PT. Adira Finacial Bandung. Melalui penelitiannya diperoleh hasil bahwa penambahan atau pengurangan modal kerja akan mempengaruhi rentabilitas.

Berdasarkan uraian diatas peneliti tertarik untuk melakukan penelitian mengenai kondisi keuangan PT. Bukit Agung Sehati Palembang dan bagaimana kinerja keuangan tahun kedepan. Dan berangkat dari hal inilah, penulis tertarik untuk menganalisis hubungan rasio finansial tersebut dan menuangkannya dalam bentuk proposal dengan judul : "PENGARUH MODAL 


\section{TINJAUAN PUSTAKA}

\subsection{Landasan Teori}

\subsubsection{Pengertian Modal Kerja}

Menurut Kasmir (2018 : 250)

modal kerja merupakan modal yang digunakan untuk melakukan kegiatan operasi perusahaan. Modal kerja juga dapat diartikan sebagai investasi yang ditanamkan dalam aktiva lancar.

Apabila perusahaan kekurangan modal kerja untuk memperluas penjualan dan meningkatkan produksinya, maka besar kemungkinan akan kehilangan pendapat an dan keuntungan. Perusahaan yang tidak memiliki modal kerja yang cukup, tidak dapat membayar kewajibannya tepat pada waktunya dan akan menghadapi masalah keuangan. Investasi modal kerja merupakan proses terus-menerus selama perusahaan beroperasi.

Menurut Gitman (2015 :105) menjelaskan bahwa modal kerja adalah jumlah harta lancar yang merupakan bagian dari investasi yang bersirkulasi dari satu bentuk ke bentuk yang lain dalam suatu kegiatan bisnis. Weston dan Brigham (2016:98) menjelaskan bahwa manjemen modal kerja adalah investasi perusahaan dalam jangka pendek: kas, surat-surat berharga (efek), piutang,dan persediaan. Masing-masing elemen modal kerja tersebut wajib dikelola agar berada pada keadaan optimal.

Menurut Priainah dan Kusuma, (2015 : 114). Elemen-elemen perputaran modal kerja terdiri dari kas, piutang, persediaan yang merupakan elemen dari aktiva lancar.

\subsubsection{Pentingnya Moda Kerja yang cukup. \\ Modal kerja sebaiknya tersedia} dalam jumlah yang cukup agar memungkinkan perusahaan untuk beroperasi secara ekonomis dan tidak mengalami kesulitan keuangan, misalnya dapat menutup kerugian dan mengatasi keadaan krisis atau darurat tanpa membahayakan keadaan keuangan perusahaan.

Penyebab timbulnya kelebihan modal kerja adalah sebagai berikut. a. Pengeluaran saham dan obligasi yang melebihi dari jumlah yang diperlukan.

b. Penjualan aktiva tetap tanpa diikuti penempatan kembali.

c. Pendapatan atau keuntungan yang diperoleh tidak digunakan untuk membayar dividen, membeli aktiva tetap, atau maksud-maksud lainnya.

\subsubsection{Faktor- Faktor Yang Mempengaruhi Jumlah Modal Kerja \\ Menurut Munawir ( ( 2016:117)}

Faktor-faktor yang mempengaruhi jumlah modal kerja adalah sebagai berikut.

a. Sifat umum atau tipe perusahaan.

b. Waktu yang diperlukan untuk memproduksi atau mendapatkan barang dan ongkos produksi per unit atau harga beli per unit barang.

c. Syarat pembelian dan penjualan

d. Tingkat perputaran persediaan.

e. Tingkat perputaran piutang

f. Pengaruh konjungtur (business cycle) Pada periode makmur (prosperity) aktivitas perusahaan meningkat dan

g. Derajat risiko

h. Pengaruh musim

i. Credit rating dari perusahaan

\subsection{Sumber Modal Kerja}

Modal kerja menurut jenisnya dapat dibedakan menjadi dua golongan, yakni sebagai berikut.

a. Bagian modal kerja yang realatif permanen, yaitu jumlah modal kerja minimal yang harus tetap ada dalam perusahaan untuk dapat melaksanakan operasinya atau sejumlah modal kerja yang secara terus-menerus diperlukan untuk kelancaran usaha. Modal kerja permanen ini dapat dibedakan dalam:

1. Modal kerja primer, yaitu jumlah modal kerja minimum yang harus ada pada perusahaan untuk menjamin kontinuitasi usahanya. 
2. Modal kerja normal, yaitu jumlah modal kerja yang diperlukan untuk menyelenggarakan luas produksi yang normal.

b. Bagian modal kerja yang bersifat variabel, yaitu modal kerja yang jumlahnya berubah tergantung pada perubahan keadaan.

Modal kerja variabel ini dapat dibedakan dalam:

1. Modal kerja musiman, yaitu modal kerja yang jumlahnya berubah-ubah disebabkan dan fluktuasi musim.

2. Modal kerja siklis, yaitu modal kerja yang jumlahnya berubahubah disebabkan oleh fluktuasi konjungtur.

3. Modal kerja darurat, yaitu modal kerja yang jumlahya berubahubah karena adanya keadaan darurat atau mendadak yang tidak dapat diketahui atau diramalkan terlebih dahulu (Bambang Rianto, 2016:52).

\subsubsection{Penggunaan Modal Kerja}

Penggunaan modal kerja yang mengakibatkan berkurangnya aktiva lancar menurut Munawir (2016:125) adalah :

a. Pengeluaran biaya jangka pendek dan pembayaran utang-utang jangka pendek (termasuk utang dividen).

b. Adanya pemakaian prive yang berasal dari keuntungan (pada perusahaan perseorangan dan persekutuan).

c. Kerugian usaha atau kerugian insidentil yang memerlukan pengeluaran kas.

d. Pembentukan dana untuk tujuan tertentu seperti dana pensiun pegawai, pembayaran bunga obligasi yang telah jatuh tempo, penempatan kembali aktiva tidak lancar.

e. Pembelian tambahan aktiva tetap, aktiva tidak berwujud, dan investasi jangka panjang.

f. Pembayaran utang jangka panjang dan pembelian kembali saham perusahaan.

\subsubsection{Pengertian Rentabilitas}

Rentabilitas merupakan suatu indikator yang digunakan untuk menghitung kinerja suatu perusahaan. Dengan demikian maka tingkat rentabilitas yang tinggi dapat mengakibatkan penerimaan yang tinggi pula. Menurut Bambang Riyanto (2016:114) pengertian rentabilitas, yaitu: "Rentabilitas adalah kemampuan suatu perusahaan untuk menghasilkan laba selama periode tertentu" Sedangkan pengertian rentabilitas yang dikemukakan oleh (S. Munawir 2016:99) , yaitu: "Menunjukan kemampuan perusahaan untuk menghasilkan laba selama periode tertentu",sementara itu menurut I Made Sudana (2016:103) rentabilitas yaitu: "Kemampuan perusahaan untuk menghasilkan laba dengan menggunakan sumber-sumber yang dimiliki perusahaan, seperti aktiva, modal atau penjualan perusahaan.

Menurut Sutrisno (2018:187) menyatakan bahwa: "Rentabilitas adalah rasio keuntungan untuk mengukur seberapa besar tingkat keuntungan yang dapat diperoleh perusahaan, semakin besar tingkat keuntungan menunjukan semakin baik manajemen dalam mengelola perusahaan" .Rasio rentabilitas bertujuan untuk mengetahui kemampuan bank dalam menghasilkan laba selama periode tertentu, juga bertujuan untuk mengukur tingkat efektifitas manajemen dalam menjalankan operasional perusahaannya.

\subsubsection{Fungsi Rentabilitas}

Seperti rasio-rasio yang lain, rasio rentabilitas juga memiliki fungsi, tidak hanya bagi pemilik usaha atau manajemen saja, tetapi juga bagi pihak di luar perusahaan, terutama pihakpihak yang memiliki hubungan atau kepentingan dengan perusahaan. 
Fungsi dari rasio rentabilitas adalah untuk:

1. Mengetahui besarnya tingkat laba yang diperoleh perusahaan dalam satu periode

2. Mengetahui posisi laba perusahaan tahun sebelimnya dengan tahun sekarang

3. Mengetahui perkembangan laba dari waktu ke waktu

4. Mengetahui besarnya laba bersih sesudah pajak dengan modal sendiri

5. Mengetahui produktivitas dari seluruh dana perusahaan yang digunakan baik modal pinjaman maupun modal sendiri.

\subsubsection{Pengaruh Perputaran Modal Kerja Terhadap Rentabilitaas} Perputaran modal kerja merupakan perbandingan antara penjualan dengan jumlah keseluruhan aktiva lancar yang dimiliki suatu perusahaan pada suatu periode akuntansi tertentu. Semakin besar rasio ini menunjukan efektifnya pemanfaatan modal kerja yang tersedia dalam meningkatkan rentabilitas perusahaan. Ini berarti bahwa semakin besar rasio perputaran modal kerja maka semakin baik suatu perusahaan dimana persentase modal kerja yang ada mampu menghasilkan jumlah penjualan tertentu. Tingkat perputaran modal kerja mengukur berapa kali aktia lancar mampu berputar untuk menghasilkan penjualan. Semakin cepat modal kerja berputar semakin banyak penjualan yang berhasil tercipta. Dengan peningkatan penjualan dapat dipastikan terjadi peningkatan profitabilitas. Working capital turnover ratio digunakan untuk mengukur perputaran modal kerja yaitu rasio penjualan terhadap aktiva lancar. Penelitian yang dilakukan oleh Raheman dan Nasr (2007) yang menyatakan bahwa working capital turnover ratio berpengaruh positif signifikan terhadap tingkat profitabilitas perusahaan di Pakistan.

\subsection{Hipotesis}

Dalam penelitian ini diajukan sebuah hipotesis sebagai jawaban sementara terhadap permasalahan yang telah dikemukakan. Adapun hipotesis yang diajukan dalam penelitian ini adalah : "Ada modal kerja terhadap rasio rentabilitas".

\section{Metode Penelitian}

\subsection{Obyek Penelitian}

Penelitian ini dilakukan di PT. Bukit Agung Sehati Palembang yang beralamat di Jalan Padat Karya Rt.4 No.18 Kelurahan Talang Buluh Kecamatan Talang Kelapa Kabupaten Banyuasin.

\subsection{Ruang Lingkup Penelitian}

Ruang lingkup penelitian adalah Modal Kerja terhadap kinerja keuangan di PT. Bukit Agung Sehati Palembang, laporan keuangan yaitu Neraca dan Rugi- laba

\subsection{Desain Penelitian}

Desain penelitian merupakan pedoman yang digunakan dalam proses penelitian, oleh karena itu perlu disusun desain penelitian yang sistematis untuk menentukan langkah-langkah yang akan dilakukan dalam penelitian. Objek dari penelitian ini adalah berkaitan atau pengaruh Modal kerja terhadap kinerja keuangan pada PT. Bukit Agung Sehati Palembang tahun 2015-2019. Penulis menggunakan jenis penelitian ini dengan alasan bahwa setiap perusahaan mempunyai suatu keadaa atau kondisi yang berbeda-beda, hal ini disebabkan adanya nperbedaan besar kecilnya perusahaan dan jenis perusahaan.

Pengertian studi kasus dijelaskan oleh Djahidin (2015:66) sebagai berikut : "Studi kasus adalah peneltian tentang status obyek penelitian yang berkenan dengan fase spesifik atau khas dari keseluruhan personalitas. Subyek penelitian pendapat saja individu, kelompok, lembaga ataupun masyarakat" 


\subsection{Teknik Analisis Data}

Dalam penyusunan proposal skripsi akhir ini, penulis menggunakan tehnik analisis kualitatif, yaitu tehnik analisis yang di pakai guna menganalisis Pengaruh penggunaan modal kerja terhadap rasio profitabilitas secara kualitatif (perbandingan praktek lapangan dengan teori yang di dapat penulis dibangku kuliah).

\subsubsection{Metode Analisis Regresi Linier} Sederhana

$\begin{array}{ccr}\text { Analisis } & \text { Regresi linear } \\ \text { sederhana yaitu analisis yang }\end{array}$ digunakan untuk menghitung pengaruh variabel independen (X) terhadap variabel dependen $(\mathrm{Y})$ apabila terjadi perubahan pada satu satuan dari variabel independen $(\mathrm{X})$.

Rumus yang digunakan adalah:

$$
\begin{aligned}
& Y=a+b x \\
& a=\frac{\Sigma y_{1}}{n}-b \frac{\Sigma x_{1}}{n} \\
& b=\frac{n \Sigma x_{1} y_{1}-\frac{n \Sigma x_{1 \Sigma}}{n \Sigma x_{1}}-\left(\Sigma x_{1}\right)^{2}}{2}
\end{aligned}
$$

Dimana :

$\mathrm{Y}=$ Rasio Profitabilitas

$\mathrm{a}=$ Koefisien regresi konstan

$\mathrm{X}=$ Modal kerja

$\mathrm{b}=$ Koefisien regresi independen pertama

Koefisien determinasi (R2),
digunakan untuk melihat
besarnya pengaruh variable $\mathrm{X}$
terhadap Y.
Koefesien diterminasi dengan
simbol $\mathrm{r}^{2}$ merupakan proporsi
variabilitas dalam suatu data yang dihitung didasarkan pada model statistik. Definisi berikutnya menyebutkan bahwa $r^{2}$ merupakan rasio variabilitas nilai-nilai yang dibuat model dengan variabilitas nilai data asli. Secara umum $r^{2}$ digunakan sebagai informasi mengenai kecocokan suatu model. Dalam regresi $\mathrm{r}^{2}$ ini dijadikan sebagai pengukuran seberapa baik garis regresi mendekati nilai data asli yang dibuat model. Jika $\mathrm{r}^{2}$ sama dengan 1 , maka angka tersebut menunjukkan garis regresi cocok dengan data secara sempurna. Interpretasi lain ialah bahwa $r^{2}$ diartikan sebagai proporsi variasi tanggapan yang diterangkan oleh regresor (variabel bebas $/ \mathrm{X}$ ) dalam model. Dengan demikian, jika $r^{2}=1$ akan mempunyai arti bahwa model yang sesuai menerangkan semua variabilitas dalam variabel $Y$. jika $r^{2}=0$ akan mempunyai arti bahwa tidak ada hubungan antara regresor (X) dengan variabel $\mathrm{Y}$.

\section{HASIL DAN PEMBAHASAN}

\subsection{Analisa Rasio Keuangan}

Untuk menganalisa atau menentukan rasio keuangan suatu perusahaan ada beberapa macam rasio, namun dalam penelitian ini peneliti hanya menggunakan dua rasio yaitu rasio likuiditas dan rasio profitabilitas seperti yang telah penulis kemukakan sebelumnya.

\subsubsection{Rasio Likuiditas}

Rasio likuiditas adalah tingkat kemampuan perusahaan untuk memenuhi kewajibannya yang harus segera dipenuhi dan likuiditas menunjukan tingkat kemampuan perusahaan untuk membayar hutanghutang jangka pendek yang dimilikinya.

\subsubsection{Rasio Rentabilitas}

Rentabilitas adalah kemampuan perusahaan memperoleh laba melalui operasional usahanya dengan menggunakan dana aset yang dimiliki oleh perusahaan. Menurut sartono (2012) profitabilitas adalah kemampuan perusahaan memperoleh laba dalam hubungannya dengan penjualan, total aktiva maupun modal sendiri 
Tabel 4.2.1

Profit Margin Rasio Rentabilitas

PT. Bukit Agung Sehati Palembang

\begin{tabular}{|c|c|c|c|c|}
\hline Tahun & Laba Operasional & Total Pendapatan & $\begin{array}{c}\text { P.M } \\
\text { Rentabilitas }\end{array}$ & Hasil Penelitian \\
\hline 2015 & 178.135 .885 & 150.252 .375 & 118,55 & Tahun Dasar \\
\hline 2016 & 184.820 .427 & 150.648 .216 & 122,68 & Menurun \\
\hline 2017 & 163.738 .726 & 152.252 .375 & 107,54 & Menurun \\
\hline 2018 & 168.134 .567 & 155.648 .216 & 108,02 & Meningkat \\
\hline 2019 & 177.196 .351 & 164.500 .000 & 107,72 & Menurun \\
\hline
\end{tabular}

Sumber : Diolah dari Laporan Laba Rugi PT. Bukit Agung Sehati Palembang

Profit Margin Rasio

Rentabilitas untuk mengukur laba bruto per Rp. 1,00 penjualan pada Tahun 2015 adalah $118,55 \%$, pada tahun 2016 mengalami kemunduran sedikit sebesar $4,13 \%$ yaitu mencapai $122,68 \%$, dan pada tahun 2017 mengalami penurunan kembali sebesar $15,14 \%$ yaitu sebesar 107,54\%, Pada tahun 2018 mengalami peningkatan sebesar $1 \%$ yaitu mencapai $108,2 \%$ dan pada tahun 2019 juga mengalami kemunduran sebesar $1 \%$ yaitu mencapai $107,72 \%$ .hal ini menunjukan Rentabilitaas pada
PT.Bukit Agung Sehati Palembang adalah kurang baik karena kelima tahun tersebut mengalami kenaikan stabil setiap tahunnya maka efeknya keuntungan yang di dapat bisa digunakan perusahaan dalam kegiatan operasionalnya ataupun digunakan untuk investasi perusahaan, dan mulai tahun 2015 mengalami penurunan ini diakibatkan oleh Harga Pokok Penjualan yang tinggi di tahun ini yang menyababkan profit Marginnya menurun.

\subsubsection{Net Profit Margin}

Tabel 4.2.2

Net Profit Margin

PT. Bukit Agung Sehati Palembang

\begin{tabular}{|c|c|c|c|c|c|}
\hline Tahun & Laba Bersih & Penjualan & $\begin{array}{c}\text { Net } \\
\text { Profit }\end{array}$ & $\begin{array}{c}\text { Standar } \\
\text { Rasio }\end{array}$ & Hasil Penelitian \\
\hline 2015 & 150.252 .375 & 828.635 .110 & $18,13 \%$ & $20 \%$ & dibawah standar \\
\hline 2016 & 150.648 .216 & 928.635 .110 & $16,22 \%$ & $20 \%$ & dibawah standar \\
\hline 2017 & 152.252 .375 & 828.635 .110 & $18,37 \%$ & $20 \%$ & dibawah standar \\
\hline 2018 & 155.648 .216 & 928.635 .110 & $16,76 \%$ & $20 \%$ & dibawah standar \\
\hline 2019 & 164.500 .000 & 949.635 .110 & $17,32 \%$ & $20 \%$ & dibawah standar \\
\hline
\end{tabular}

Net Profit Margin untuk mengukur keuntungan neto per rupiah penjualan pada tahun 2015 yaitu mencapai $26,89 \%$,dan pada tahun 2016 mengalami penurunan1,61 \% yaitu mencapai $26,48 \%$ dan pada tahun 2017 mengalami kenaikan sebanyak $0,56 \%$ yaitu mencapai $24,76 \%$, begitu juga tahun 2018 dan 2019 mengalami penurunan juga dari kelima tahun diatas dapat dilihat bahwa pada PT. Bukit Agung Sehati Palembang Net Profit Marginnya sudah diatas standar industrial yang baik yaitu $20 \%$ dari kelima tahun tersebut. 
Tabel 4.2.4

ROI

PT. Bukit Agung Sehati Palembang

\begin{tabular}{|c|c|c|c|c|l|}
\hline Tahun & $\begin{array}{c}\text { Netto Sesudah } \\
\text { Pajak }\end{array}$ & Jumlah Aktiva & $\begin{array}{c}\text { Standar } \\
\text { Rasio }\end{array}$ & R O I & Hasil Penelitian \\
\hline 2015 & 150.252 .375 & 485.189 .123 & $30 \%$ & $30,96 \%$ & Tahun Dasar \\
\hline 2016 & 150.648 .216 & 482.494 .348 & $30 \%$ & $31,22 \%$ & Diatas Standar \\
\hline 2017 & 152.252 .375 & 477.650 .500 & $30 \%$ & $31,80 \%$ & Diatas Standar \\
\hline 2018 & 155.648 .216 & 495.150 .500 & $30 \%$ & $31,40 \%$ & Diatas Standar \\
\hline 2019 & 164.500 .000 & 499.750 .500 & $30 \%$ & $32,90 \%$ & Diatas Standar \\
\hline
\end{tabular}

Net Earning Power Ratio (ROI) untuk mengukur kemampuan dari modal yang diinvestasikan dalam keseluruhan aktiva untuk menghasilkan keuntungan netto pada tahun 2015 mencapai $30,96 \%$ dan pada tahun 2016 mengalami kenaikan yaitu mencapai $31,22 \%$, dan pada tahun 2017 mengalami kenaikan juga sebesar
$31,80 \%$, dan pada tahun 2018 mengalamai penurunan sebesar $31,40 \%$ dan tahun 2019 mencapai $32,90 \%$ dari kelima tahun diatas dapat dilihat bahwa PT. Buli Agung Sehati Palembang untuk Net earning power ratio sudah diatas standar $30 \%$. ini berarti kemampuan modal menghasilkan keuntungan netto adalah baik.

\subsubsection{Return On Equity (ROE)}

Tabel 4.2.5

Return On Equity (ROE)

PT. Bukit Agung Sehati Palembang

\begin{tabular}{|c|c|l|c|c|}
\hline TAHUN & Net Income & Equity & ROE & Hasil Peneltian \\
\hline 20 & 150.252 .375 & 885.626 .790 & 0,17 & Tahun Dasar \\
\hline 20 & 150.648 .216 & 838.130 .440 & 0,18 & Meningkat \\
\hline 20 & 152.252 .375 & 821.755 .375 & 0,18 & Tetap \\
\hline 20 & 155.648 .216 & 830.494 .716 & 0,18 & Tetap \\
\hline 20 & 164.500 .000 & 856.139 .108 & 0,19 & Meningkat \\
\hline
\end{tabular}

Sumber : Diolah dari Neraca dan Laporan Laba Rugi PT. Bukit Agung Sehati Palembang

Berdasarkan perhitungan diatas terlihat bahwa untuk tahun 2015 setiap rupiah modal kerja perusahaan akan menghasilkan laba sebesar Rp. 0,17 dan pada tahun 2016 setiap rupiah modal kerja perusahaan akan menghasilkan kenaika laba sebesar Rp. 0,18 serta pada tahun 2017 setiap rupiah modal kerja perusahaan mengalami kenaikan sebesar Rp. 0,18. Pada tahun 2018 setiap rupiah modal kerja perusahaan mengalami kenaikan kembali dengan menghasilkan laba Rp.
0,18 dan pada tahun 2019 mengalami peningkatan sebesar 0,19 .

\subsubsection{Teknik Analisis Data}

\subsubsection{Uji Regresi Linier Sederhana}

Analisis regresi linier sederhana bertujuan untuk mengetahui bagaimana pengaruh variabel indenpenden terhadap variabel dependent. Untuk mengetahui kuat lemahnya pengaruh dari modal kerja terhadap rentabilitas dapat dilihat dari koefisien regrfesi.

Adapun hasil analisis regrfesi linier sederhana sebagai berikut : 
Tabel 4.3

Hasil Uji Regresi Linier Sederhana Antara Cash Ratio Terhadap ROI

Coefficients $^{\mathrm{a}}$

\begin{tabular}{|c|c|c|c|c|c|}
\hline \multirow[t]{2}{*}{ Model } & \multicolumn{2}{|c|}{$\begin{array}{c}\text { Unstandardized } \\
\text { Coefficients }\end{array}$} & $\begin{array}{c}\text { Standardized } \\
\text { Coefficients }\end{array}$ & $\mathrm{t}$ & Sig. \\
\hline & $\mathrm{B}$ & Std. Error & Beta & & \\
\hline (Constant) &, 315 &, 110 & & 2,874 & ,064 \\
\hline $\begin{array}{ll} & \text { CASH } \\
1 & \text { RATIO }\end{array}$ & 019 & ,017 & 543 & 1,120 & 344 \\
\hline
\end{tabular}

a. Dependent Variable: ROI

Sumber : pengolahan data primer dengan SPSS 22

Dari hasil perhitungan tabel 4.7 maka dapat dibentuk persamaan regresi yaitu : $Y=0,315+0,019 X$

Tabel 4.4

Hasil Uji Regresi Linier Sederhana Antara Cash Ratio Terhadap ROE

Coefficients $^{\mathrm{a}}$

\begin{tabular}{|c|c|c|c|c|c|}
\hline \multirow[t]{2}{*}{ Model } & \multicolumn{2}{|c|}{$\begin{array}{c}\text { Unstandardized } \\
\text { Coefficients }\end{array}$} & $\begin{array}{c}\text { Standardized } \\
\text { Coefficients }\end{array}$ & $\mathrm{t}$ & Sig. \\
\hline & $\mathrm{B}$ & Std. Error & Beta & & \\
\hline (Constant) & ,333 & ,115 & & 2,903 & ,062 \\
\hline $\begin{array}{ll}\text { 1 } & \text { CASH } \\
\text { RATIO }\end{array}$ & ,018 & ,018 & ,507 & 1,019 & 383 \\
\hline
\end{tabular}

a. Dependent Variable: ROE

Sumber : pengolahan data primer dengan SPSS 22

Dari hasil perhitungan tabel 4.4 maka dapat dibentuk persamaan regresi yaitu $\mathbf{Y}=\mathbf{0 , 3 3 3 + 0 , 0 1 8 X}$

Tabel 4.5

Hasil Uji Regresi Linier Sederhana Antara Cash Ratio Terhadap NPM

Coefficients $^{\mathbf{a}}$

\begin{tabular}{|c|c|c|c|c|c|}
\hline \multirow[t]{2}{*}{ Model } & \multicolumn{2}{|c|}{$\begin{array}{c}\text { Unstandardized } \\
\text { Coefficients }\end{array}$} & $\begin{array}{l}\text { Standardized } \\
\text { Coefficients }\end{array}$ & \multirow[t]{2}{*}{$\mathrm{t}$} & \multirow[t]{2}{*}{ Sig. } \\
\hline & $\mathrm{B}$ & Std. Error & Beta & & \\
\hline (Constant) &, 539 &, 058 & & 9,326 & ,003 \\
\hline $\begin{array}{ll}\text { 1 CASH } \\
\text { RATIO }\end{array}$ &,- 012 & ,009 &,- 627 & $-1,392$ & 258 \\
\hline
\end{tabular}

a. Dependent Variable: NPM

Sumber : pengolahan data primer dengan SPSS 22

Dari hasil perhitungan tabel 4.4 maka dapat dibentuk persamaan regresi yaitu $\mathrm{Y}=\mathbf{0 , 5 3 9 + - 0 , 0 1 2 X}$ 
Tabel 4.6

Hasil Uji Regresi Linier Sederhana Antara Current Ratio Terhadap ROI

Coefficients $^{\mathrm{a}}$

\begin{tabular}{|l|r|r|r|r|r|}
\hline Model & \multicolumn{2}{|c|}{$\begin{array}{c}\text { Unstandardized } \\
\text { Coefficients }\end{array}$} & $\begin{array}{c}\text { Standardized } \\
\text { Coefficients }\end{array}$ & \multirow{2}{*}{ Sig. } \\
\cline { 2 - 6 } & \multicolumn{1}{|c|}{ B } & Std. Error & Beta & \\
\hline \multirow{2}{*}{$\begin{array}{l}\text { (Constant) } \\
\text { CURRENT }\end{array}$} &, 338 &, 137 & & 2,463 &, 091 \\
RATIO &, 006 &, 009 &, 382 &, 715 &, 526 \\
\hline
\end{tabular}

a. Dependent Variable: ROI

Sumber : pengolahan data primer dengan SPSS 22

Dari hasil perhitungan tabel 4.6 maka dapat dibentuk persamaan regresi yaitu $\mathbf{Y}=\mathbf{0 , 3 3 8}+\mathbf{0 , 0 0 6 X}$

Tabel 4.7

Hasil Uji Regresi Linier Sederhana Antara Current Ratio Terhadap ROE

Coefficients $^{\mathrm{a}}$

\begin{tabular}{|l|r|r|c|r|r|}
\hline Model & \multicolumn{2}{|c|}{$\begin{array}{c}\text { Unstandardized } \\
\text { Coefficients }\end{array}$} & $\begin{array}{c}\text { Standardized } \\
\text { Coefficients }\end{array}$ & \multirow{2}{*}{ Sig. } \\
\cline { 2 - 5 } & \multicolumn{1}{|c|}{ B } & Std. Error & Beta & \\
\hline (Constant) &, 359 &, 142 & & 2,521 &, 086 \\
CURRENT &, 006 &, 009 &, 341 &, 628 &, 574 \\
RATIO & & & & & \\
\hline
\end{tabular}

a. Dependent Variable: ROE

Sumber : pengolahan data primer dengan SPSS 22

Dari hasil perhitungan tabel 4.7 maka dapat dibentuk persamaan regresi yaitu $\mathrm{Y}=\mathbf{0 , 3 5 9 + 0 , 0 0 6 \mathrm { X }}$

Tabel 4.8

Hasil Uji Regresi Linier Sederhana Antara Current Terhadap NPM Coefficients $^{\mathrm{a}}$

\begin{tabular}{|c|c|c|c|c|c|}
\hline \multirow[t]{2}{*}{ Model } & \multicolumn{2}{|c|}{$\begin{array}{c}\text { Unstandardized } \\
\text { Coefficients }\end{array}$} & $\begin{array}{l}\text { Standardized } \\
\text { Coefficients }\end{array}$ & \multirow[t]{2}{*}{$\mathrm{t}$} & \multirow[t]{2}{*}{ Sig. } \\
\hline & $\mathrm{B}$ & Std. Error & Beta & & \\
\hline (Constant) &, 539 &, 071 & & 7,636 & 005, \\
\hline $\begin{array}{ll}1 & \text { CURRENT } \\
\text { RATIO }\end{array}$ &,- 005 & ,004 &,- 546 & $-1,128$ & 341, \\
\hline
\end{tabular}

a. Dependent Variable: NPM

Sumber : pengolahan data primer dengan SPSS 22

Dari hasil perhitungan tabel 4.8 maka dapat dibentuk persamaan regresi yaitu $\mathrm{Y}=\mathbf{0 , 5 3 9 + - 0 , 0 0 5 X}$ 
Tabel 4.9

Hasil Uji Regresi Linier Sederhana Antara WCTA Terhadap ROI

Coefficients $^{\mathrm{a}}$

\begin{tabular}{|c|c|c|c|c|c|}
\hline \multirow[t]{2}{*}{ Model } & \multicolumn{2}{|c|}{$\begin{array}{l}\text { Unstandardized } \\
\text { Coefficients }\end{array}$} & $\begin{array}{l}\text { Standardized } \\
\text { Coefficients }\end{array}$ & \multirow[t]{2}{*}{$\mathrm{t}$} & \multirow[t]{2}{*}{ Sig. } \\
\hline & $\mathrm{B}$ & Std. Error & Beta & & \\
\hline (Constant) &,- 024 & ,322 & & $-0,74$ & ,946 \\
\hline 1 WCTA & 1,171 & 824, & .634 & 1,420 & 251 \\
\hline
\end{tabular}

a. Dependent Variable: ROI

Sumber : pengolahan data primer dengan SPSS 22

Dari hasil perhitungan tabel 4.9 maka dapat dibentuk persamaan regresi yaitu $Y=-\mathbf{0 , 0 2 4}+\mathbf{1 , 1 7 1 X}$

Tabel 4.10

Hasil Uji Regresi Linier Sederhana Antara WCTA Terhadap ROE

Coefficients $^{\mathrm{a}}$

\begin{tabular}{|c|c|c|c|c|c|}
\hline \multirow[t]{2}{*}{ Model } & \multicolumn{2}{|c|}{$\begin{array}{c}\text { Unstandardized } \\
\text { Coefficients }\end{array}$} & $\begin{array}{c}\text { Standardized } \\
\text { Coefficients }\end{array}$ & \multirow[t]{2}{*}{$\mathrm{t}$} & \multirow[t]{2}{*}{ Sig. } \\
\hline & B & Std. Error & Beta & & \\
\hline (Constant) &,- 022 &, 328 & & $-0,69$ & ,950 \\
\hline 1 WCTA & 1,200 & ,839 & 637 & 1,430 & 248 \\
\hline
\end{tabular}

a. Dependent Variable: ROE

Sumber : pengolahan data primer dengan SPSS 22

Dari hasil perhitungan tabel 4.8 maka dapat dibentuk persamaan regresi yaitu $Y=\mathbf{- 0 , 0 2 2 + 1 , 2 0 0 X}$

Tabel 4.11

Hasil Uji Regresi Linier Sederhana Antara WCTA Terhadap NPM Coefficients $^{\mathrm{a}}$

\begin{tabular}{|c|c|c|c|c|c|}
\hline \multirow[t]{2}{*}{ Model } & \multicolumn{2}{|c|}{$\begin{array}{c}\text { Unstandardized } \\
\text { Coefficients }\end{array}$} & $\begin{array}{l}\text { Standardized } \\
\text { Coefficients }\end{array}$ & \multirow[t]{2}{*}{$\mathrm{t}$} & \multirow[t]{2}{*}{ Sig. } \\
\hline & $\mathrm{B}$ & Std. Error & Beta & & \\
\hline (Constant) & ,679 & ,207 & & 3,384 & ,043 \\
\hline 1 WCTA &,- 557 & 513 &,- 531 & $-1,086$ & 357 \\
\hline
\end{tabular}

a. Dependent Variable: NPM

Sumber : pengolahan data primer dengan SPSS 22

Dari hasil perhitungan tabel 4.11 maka dapat dibentuk persamaan regresi yaitu $\mathrm{Y}=0,679+-0,557 \mathrm{X}$

\subsubsection{Uji Parsial (Uji t)}

Pengujian ini dilakukan untuk mengetahui signifikan peran secara parsial atau sendiri-sendiri antara variabel indenpenden terhaddap variabel dependen dengan mengasumsikan bahwa vaiabel indenpenden lain dianggap konstan.

Hipotesis penelitian ini adalah :

- Ho : $\beta=0$ : tidak terdapat pengaruh yang signifikan

- Ho: $\beta \neq 0$ : terapat pengaruh yang signifikan

Dengan kriteria yang dapat digunakan sebagai berikut : 
- Ho diterima jika nilai $\mathrm{t}_{\text {hitung }} \leq \mathrm{t}_{\text {tabel }}$ atau nilai sig $>\alpha$

- Ho ditolak jika nilai $\mathrm{t}_{\text {hitung }} \geq \mathrm{t}_{\text {tabel }}$ atau nilai sig $<\alpha$

- level signifikansi $(\alpha)$ dengan nilai $\alpha=0,05$

Sedangkan untuk melihat besarnya penagruh digunakan angka Beta atau standardized Coefficient dibawah ini :

Tabel 4.12

Hasil Uji Parsial (Uji-t) Antara Cash Ratio Terhadap ROI

Coefficients $^{\mathrm{a}}$

\begin{tabular}{|c|c|c|c|c|c|}
\hline \multirow[t]{2}{*}{ Model } & \multicolumn{2}{|c|}{$\begin{array}{l}\text { Unstandardized } \\
\text { Coefficients }\end{array}$} & $\begin{array}{c}\text { Standardized } \\
\text { Coefficients }\end{array}$ & \multirow[t]{2}{*}{$\mathrm{t}$} & \multirow[t]{2}{*}{ Sig. } \\
\hline & B & Std. Error & Beta & & \\
\hline (Constant) & ,315 &, 110 & & 2,874 &, 064 \\
\hline $\begin{array}{ll}1 & \text { CASH } \\
\text { RATIO }\end{array}$ & ,019 &, 017 & ,543 & 1,120 & ,344 \\
\hline
\end{tabular}

a. Dependent Variable: ROI

Hasil Uji-t dapat dijelaskan bahwa nilai t hitung untuk varibael Casg Ratio (X1) sebesar 1,120 dan nilai signifikansinya (sig) sebesar 0,344. Nilai signifikan tersebut lebih besar daari 0,05 . Berarti bisa disimpulkan bahwa data tersebut bersifat positif dan juga menunjukkan bahwa tidak berpengaruh secara signifikan antara Cash Ratio (X1) dengan ROI (Y1).

Tabel 4.13

Hasil Uji Parsial (Uji-t) Antara Cash Ratio Terhadap ROE

Coefficients $^{\mathrm{a}}$

\begin{tabular}{|l|r|r|r|r|r|}
\hline Model & \multicolumn{2}{|c|}{$\begin{array}{l}\text { Unstandardized } \\
\text { Coefficients }\end{array}$} & $\begin{array}{c}\text { Standardized } \\
\text { Coefficients }\end{array}$ & \multirow{2}{*}{ Sig. } & \\
\cline { 2 - 5 } & \multicolumn{1}{|c|}{ B } & Std. Error & \multicolumn{1}{c|}{ Beta } & & \\
\hline (Constant) &, 333 &, 115 & & 2,903 &, 062 \\
1 CASH &, 018 &, 018 &, 507 & 1,019 &, 383 \\
RATIO & & & & & \\
\hline
\end{tabular}

a. Dependent Variable: ROE

Hasil Uji-t dapat dijelaskan bahwa nilai t hitung untuk variabel Cash Ratio (X1) sebesar 1,019 dan nilai signifikansinya (sig) sebesar 0,383. Nilai signifikan tersebut lebih besar dari 0,05. Berarti bisa disimpulkan bahwa data tersebut bersifat positif dan juga menunjukkan bahwa tidak berpengaruh secara signifikan antara Cash Ratio (X1) dengan ROE (Y2).

Tabel 4.14

Hasil Uji Parsial (Uji-t) Antara Cash Ratio Terhadap NPM

Coefficients $^{\mathbf{a}}$

\begin{tabular}{|c|c|c|c|c|c|}
\hline \multirow[t]{2}{*}{ Model } & \multicolumn{2}{|c|}{$\begin{array}{c}\text { Unstandardized } \\
\text { Coefficients }\end{array}$} & $\begin{array}{c}\text { Standardized } \\
\text { Coefficients }\end{array}$ & $\mathrm{t}$ & Sig. \\
\hline & $\mathrm{B}$ & Std. Error & Beta & & \\
\hline (Constant) &, 539 &, 058 & & 9,326 & ,003 \\
\hline $\begin{array}{ll}1 & \text { CASH } \\
\text { RATIO }\end{array}$ &,- 012 & ,009 &,- 627 & $-1,392$ & ,258 \\
\hline
\end{tabular}

a. Dependent Variable: NPM 
Hasil Uji-t dapat dijelaskan bahwa nilai t hitung untuk variabel Cash Ratio (X1) sebesar 1,392 dan nilai signifikansinya (sig) sebesar 0,258. Nilai signifikan tersebut lebih besar dari 0,05 . Berarti bisa disimpulkan bahwa data tersebut bersifat positif dan juga menunjukkan bahwa tidak berpengaruh secara signifikan antara Cash Ratio (X1) dengan NPM (Y3).

Tabel 4.15

Hasil Uji Parsial (Uji-t) Antara Current Ratio Terhadap ROI Coefficients $^{\mathrm{a}}$

\begin{tabular}{|c|c|c|c|c|c|}
\hline \multirow[t]{2}{*}{ Model } & \multicolumn{2}{|c|}{$\begin{array}{c}\text { Unstandardized } \\
\text { Coefficients }\end{array}$} & $\begin{array}{l}\text { Standardized } \\
\text { Coefficients }\end{array}$ & \multirow[t]{2}{*}{$\mathrm{t}$} & \multirow[t]{2}{*}{ Sig. } \\
\hline & $\mathrm{B}$ & Std. Error & Beta & & \\
\hline 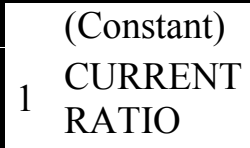 & ,338 & ,137 & ,382 & $\begin{array}{r}2,463 \\
, 715\end{array}$ & ,526 \\
\hline
\end{tabular}

a. Dependent Variable: ROI

Sumber : pengolahan data primer dengan SPSS 22

Hasil Uji-t dapat dijelaskan bahwa nilai t hitung untuk variabel Current Ratio (X2) sebesar 0,715 dan nilai signifikansinya (sig) sebesar 0,526. Nilai signifikan tersebut lebih besar dari 0,05. Berarti bisa disimpulkan bahwa data tersebut bersifat positif dan juga menunjukkan bahwa tidak berpengaruh secara signifikan antara Current Ratio (X2) dengan ROI (Y2).

Tabel 4.16

Hasil Uji Parsial (Uji-t) Antara Current Ratio Terhadap ROE

Coefficients $^{\mathrm{a}}$

\begin{tabular}{|c|c|c|c|c|c|}
\hline \multirow[t]{2}{*}{ Model } & \multicolumn{2}{|c|}{$\begin{array}{c}\text { Unstandardized } \\
\text { Coefficients }\end{array}$} & $\begin{array}{l}\text { Standardized } \\
\text { Coefficients }\end{array}$ & \multirow[t]{2}{*}{$\mathrm{t}$} & \multirow[t]{2}{*}{ Sig. } \\
\hline & $\mathrm{B}$ & Std. Error & Beta & & \\
\hline (Constant) & ,359 & , 142 & & 2,521 & ,086 \\
\hline $\begin{array}{l}\text { CURRENT } \\
\text { RATIO }\end{array}$ & ,006 & ,009 &, 341 & 628 & ,574 \\
\hline
\end{tabular}

a. Dependent Variable: ROE

Hasil Uji-t dapat dijelaskan bahwa nilai t hitung untuk variabel Current Ratio (X2) sebesar 0,628 dan nilai signifikansinya (sig) sebesar 0,574. Nilai signifikan tersebut lebih besar dari 0,05. Berarti bisa disimpulkan bahwa data tersebut bersifat positif dan juga menunjukkan bahwa tidak berpengaruh secara signifikan antara Current Ratio (X2) dengan ROE (Y2).

Tabel 4.17

Hasil Uji Parsial (Uji-t) Antara Current Ratio Terhadap NPM

Coefficients $^{\mathrm{a}}$

\begin{tabular}{|c|c|c|c|c|c|}
\hline \multirow[t]{2}{*}{ Model } & \multicolumn{2}{|c|}{$\begin{array}{l}\text { Unstandardized } \\
\text { Coefficients }\end{array}$} & $\begin{array}{l}\text { Standardized } \\
\text { Coefficients }\end{array}$ & \multirow[t]{2}{*}{$\mathrm{t}$} & \multirow[t]{2}{*}{ Sig. } \\
\hline & B & Std. Error & Beta & & \\
\hline (Constant) & ,539 &, 071 & & 7,636 & ,005 \\
\hline $\begin{array}{l}\text { CURRENT } \\
\text { RATIO }\end{array}$ &,- 005 & ,004 &,- 546 & $-1,128$ & ,341 \\
\hline
\end{tabular}

a. Dependent Variable: NPM 
Hasil Uji-t dapat dijelaskan bahwa nilai t hitung untuk variabel Current Ratio (X3) sebesar 0,628 dan nilai signifikansinya (sig) sebesar 0,574. Nilai signifikan tersebut lebih besar dari 0,05. Berarti bisa disimpulkan bahwa data tersebut bersifat positif dan juga menunjukkan bahwa tidak berpengaruh secara signifikan antara Current Ratio (X3) dengan NPM (Y3).

Tabel 4.18

Hasil Uji Parsial (Uji-t) Antara WCTA Terhadap ROI

Coefficients $^{\mathrm{a}}$

\begin{tabular}{|l|r|r|r|r|r|}
\hline Model & \multicolumn{2}{|c|}{$\begin{array}{c}\text { Unstandardized } \\
\text { Coefficients }\end{array}$} & $\begin{array}{c}\text { Standardized } \\
\text { Coefficients }\end{array}$ & \multirow{2}{*}{ Sig } \\
\cline { 2 - 6 } & \multicolumn{1}{|c|}{ B } & Std. Error & Beta & \\
\hline \multirow{2}{*}{ (Constant) } &,- 024 &, 322 & & $-0,74$ &, 946 \\
WCTA & 1,171 &, 824 &, 634 & 1,420 &, 251 \\
\hline
\end{tabular}

a. Dependent Variable: ROI

Hasil Uji-t dapat dijelaskan bahwa nilai t hitung untuk variabel WCTA (X3) sebesar 1,420 dan nilai signifikansinya (sig) sebesar 0,251. Nilai signifikan tersebut lebih besar dari 0,05 . Berarti bisa disimpulkan bahwa data tersebut bersifat positif dan juga menunjukkan bahwa tidak berpengaruh secara signifikan antara WCTA (X3) dengan ROI (Y3).

Tabel 4.20

Hasil Uji Parsial Antara WCTA Terhadap ROE

Coefficients $^{\mathrm{a}}$

\begin{tabular}{|c|c|c|c|c|c|}
\hline \multirow[t]{2}{*}{ Model } & \multicolumn{2}{|c|}{$\begin{array}{c}\text { Unstandardized } \\
\text { Coefficients }\end{array}$} & $\begin{array}{l}\text { Standardized } \\
\text { Coefficients }\end{array}$ & \multirow[t]{2}{*}{$\mathrm{t}$} & \multirow[t]{2}{*}{ Sig. } \\
\hline & $\mathrm{B}$ & Std. Error & Beta & & \\
\hline (Constant) &,- 022 &, 328 & & $-0,69$ & ,950 \\
\hline 1 WCTA & 1,200 & ,839 & ,637 & 1,430 & ,248 \\
\hline
\end{tabular}

a. Dependent Variable: ROE

Hasil Uji-t dapat dijelaskan bahwa nilai t hitung untuk variabel WCTA (X3) sebesar 1,430 dan nilai signifikansinya (sig) sebesar 0,248. Nilai signifikan tersebut lebih besar dari 0,05. Berarti bisa disimpulkan bahwa data tersebut bersifat positif dan juga menunjukkan bahwa tidak berpengaruh secara signifikan antara WCTA (X3) dengan ROI (Y3).

Tabel 4.21

Hasil Uji Parsial Antara WCTA Terhadap NPM

Coefficients $^{\mathbf{a}}$

\begin{tabular}{|r|r|r|r|r|r|}
\hline \multirow{2}{*}{ Model } & \multicolumn{2}{|c|}{$\begin{array}{c}\text { Unstandardized } \\
\text { Coefficients }\end{array}$} & $\begin{array}{c}\text { Standardized } \\
\text { Coefficients }\end{array}$ & \multirow{2}{*}{ Sig. } & \\
\cline { 2 - 5 } & \multicolumn{1}{|c|}{ B } & Std. Error & \multicolumn{1}{c|}{ Beta } & & \\
\hline \multirow{2}{*}{$\begin{array}{l}\text { (Constant) } \\
\text { WCTA }\end{array}$} &, 679 &, 207 & & 3,384 &, 043 \\
&,- 557 &, 513 &,- 531 & $-1,086$ &, 357 \\
\hline
\end{tabular}

a. Dependent Variable: NPM

Hasil Uji-t dapat dijelaskan bahwa nilai $t$ hitung untuk variabel WCTA (X3) sebesar -1,086 dan nilai signifikansinya (sig) sebesar 0,357 . Nilai signifikan tersebut lebih besar dari 0,05. Berarti bisa disimpulkan bahwa data 
tersebut bersifat positif dan juga menunjukkan bahwa tidak berpengaruh secara signifikan antara WCTA (X3) dengan NPM (Y3).

\subsection{Pembahasan}

Berdasarkan hasil penelitian analisis regresi linier sederhana antara Cash Ratio terhadap ROI yaitu $\mathrm{Y}=0,315+0,019 \mathrm{X}$, Cash Ratio terhadap ROE yaitu $\mathrm{Y}=0,333+0,018 \mathrm{X}$, Cash Ratio terhadap NPM yaitu $\mathrm{Y}=0,539+0,012 \mathrm{X}$, Curren Ratio terhadap ROI $\mathrm{Y}=0,338+0,006 \mathrm{X}$, Current Ratio terhadap ROE $\mathrm{Y}=0,359+0,006 \mathrm{X}$, Current Ratio terhadap NPM Y $=0,539+-$ $0,005 \mathrm{X}$, WCTA terhadap ROI $\mathrm{Y}=0,024+1,171 \mathrm{X}$, WCTA terhadap ROE $Y=-0,022+1,200 X$, WCTA terhadap NPM Y=0,679+-0,557X.

Berdasarkan hasil penelitian analisis uji-t antara Cash Ratio terhadap ROI sebesar 1,120 dan nilai signifikannya (sig) sebesar 0,344 . Nilai signifikan tersebut lebih besar ari 0,05 . Berarti bisa disimpulkan bahwa data tersebut bersifat positif dan juga menunjukkan bahwa tidak berpengaruh secara signifikan. Cash Ratio terhadap ROE sebesar 1,019 dan nilai nsignifikannya (sig) sebesar 0,383 . Nilai signifikan tersebut lebih besar dari 0,05. Berarti bisa disimpulkan bahwa data tersebut bersifat positif dan juga menunjukkan bahwa tidak berpengaruh secara signifikan. Cash Ratio terhadap NPM sebesar $-1,392$ dan nilai signifikansinya (sig) sebesar 0,258 . Nilai signifikan tersebut lebih besar darin 0,05 . Berarti bisa disimpulkan bahawa data tersebut bersifat negatif dan juga menunjukkan bahwa tidak berpengaruh secara signifikan. Current Ratio terhadap ROI sebear 0,715 dan nilai signifikansinya (sig) sebear 0,574 . Nilai signifikan tersebut lebih besar dari 0,05. Berarti bisa disimpulkan bahwa data tersebut bersifat possitif dan juga menunjukkan bahwa tidak berpengaruh secara signifikan. Current Ratio terhadap ROE sebesar 0,628 dan nilai signifikansinya (sig) sebear 0,526 . Nilai signifikan tersebut lebih besar dari 0,05 . Berarti bisa disimpulkan bahwa data tersebut bersifat possitif dan juga menunjukkan bahwa tidak berpengaruh secara signifikan. Currentb Ratio terhadap NPM sebesar $-1,128$ dan nilai signifikansinya (sig) sebesar 0,341 . Nilai signifikan tersebut lebih besar dari 0,05 . Berarti bisa disimpulkan bahwa data tersebut bersifat negatif dan juga menunjukkan bahwa tidak berpengaruh secara signifikan. WCTA terhadap ROI sebear 1,420 dan nilai signifikansinya (sig) sebear 0,251. Nilai signifikan tersebut lebih besar dari 0,05. Berarti bisa disimpulkan bahwa data tersebut bersifat possitif dan juga menunjukkan bahwa tidak berpengaruh secara signifikan. WCTA terhadap ROE sebear 1,430 dan nilai signifikansinya (sig) sebear 0,248. Nilai signifikan tersebut lebih besar dari 0,05. Berarti bisa disimpulkan bahwa data tersebut bersifat possitif dan juga menunjukkan bahwa tidak berpengaruh secara signifikan. WCTA terhadap NPM sebear -1,086 dan nilai signifikansinya (sig) sebear 0,357 . Nilai signifikan tersebut lebih besar dari 0,05 . Berarti bisa disimpulkan bahwa data tersebut bersifat possitif dan juga menunjukkan bahwa tidak berpengaruh secara signifikan.

\section{KESIMPULAN DAN SARAN}

\subsection{Kesimpulan}

Penelitian ini menguji

Pengaruh Modal Kerja Terhadap Rentabilitas. Penelitian ini menguji enam variabel yang terdiri dari variabel $\mathrm{X}$ sebagai modal kerja yang terdiri dari Profit Margin, Operating Ratio dan Working Capital Total to Asset (WCTA). Dan untuk variabel $\mathrm{Y}$ sebagai rentabilitas yang terdiri dari Return On Investment (ROI), Return On Equity (ROE) dan Net Profit Margin (NPM).

Berdasarkan hasil analisis dan pengujian hipotesis dapat disimpulkan sebagai berikut :

1. Hasil penelitian analisis regresi linier sederhana beserta uji $t$ didapati pengaruh sebagai berikut :

a. Hasil pengujian menunjukkan bahwa tidak berpengaruh secara signifikan antara Cash Ratuo (X1) dan ROI (Y1) 
b. Hasil pengujian menunjukkan bahwa tidak berpengaruh secara signifikan antara Gross Profit Margin (X1) dan ROE (Y2)

c. Hasil pengujian menunjukkan bahwa tidak berpengaruh secara signifikan antara Cash Ratio (X1) dan NPM (Y3)

d. Hasil pengujian menunjukkan bahwa tidak berpengaruh secara signifikan antara Current Ratio (X2) dan ROI (Y1)

e. Hasil pengujian menunjukkan bahwa tidak berpengaruh secara signifikan antara Current Ratio (X2) dan ROE (Y2)

f. Hasil pengujian menunjukkan bahwa tidak berpengaruh secara signifikan antara Current Ratio (X2) dan NPM (Y3)

g. Hasil pengujian menunjukkan bahwa tidak berpengaruh secara signifikan antara WCTA (X3) dan ROI (Y1)

h. Hasil pengujian menunjukkan bahwa tidak berpengaruh secara signifikan antara WCTA (X3) dan ROI (Y2)

i. Hasil pengujian menunjukkan bahwa tidak berpengaruh secara signifikan antara WCTA (X3) dan ROI (Y3)

\subsection{Saran}

Adapun saran yang dapat penulis berikan pada PT.Presol Indo Prima Palembang adalah :

1. Bagi Perusahaan

a. Berdasarkan hasil penelitian diatas, rendahnya pengaruhn antara modal kerja terhadap profitabilitas pada PT. Presol Indo Prima Palembang diharapkan agar pihak perusahaan terus berupaya untuk memperbaiki dan meningkatkan kinerja keuangan dalam hal keuntungan bersih keuangan. b. Berdasarkan hasil penelitian diatas, bervariatifnya hubungan antara modal kerja terhadap profitabilitas pada PT.Presol Indo Prima Palembang menandakan bahwa adanya ketidak seimbangan, maka dari itu diharapkan pihak perusahaan dapat lebih memperhatikan komponen-komponen sehingga dapat terciptanya hubungan yang selaras atau positif

2. Bagi Penelitian Selanjutnya Diharapkan dapat menggunakan penelitian ini untuk mengembangkan lebih lanjut dalam menganalisis penagruh dan hubungan, yaitu dengan menambah periode penelitian, mengganti penelitian dengan objek yang lain, serta menambah variabel lainnya sehingga dapat memperbaiki penelitian sebelumnya.

\section{DAFTAR PUSTAKA}

Ati Susanti, dengan judul "Pengaruh Perputaran Modal Kerja Terhadap Profitabilitas" Cetakan Kesembilan, Penerbit Cipta,Jakarta,2016

Ariyanto, Dasar-Dasar Modal Kerja, Cetakan Kesembilan, Penerbit Cipta,Jakarta,2010

Alwi, Syafarudin, Alat-alat Analisis dalam pembelanjaan, Yogyakarta, Andi offset, 2005

Bhaduri, Analisis Laporan Keuangan, Yogyakarta, Liberty, 2012

Djahidin, Peneltian tentang status obyek penelitian, 2015

Fahmi, Irham. 2014. Analisis Kinerja Keuangan. cet 3. Bandung : Alfabeta

Gitman. 2015. Analisis Multiva riate Lanjutan dengan Program SPSS. Badan Penerbit Universitas Diponegoro. Semarang.

Jumingan, 2016, Dasar-Dasar Modal Kerja, Cetakan Kesembilan, Penerbit Cipta,Jakarta,2016 
Kasmir. 2018. Analisis Faktor-Faktor Yang Mem pengaruhi Ketepatan Waktu Penyam paian Laporan Keuangan. Simpo sium Nasional Akuntansi XI Ikatan Indonesia. H.1-22.

Munawir. Dasar-Dasar Modal Kerja, Jakarta,2016

Priainah dan Kusuma, Analisis Laporan Keuangan, Yogyakarta, Liberty, 2015.

Riyanto, Bambang, Dasar-dasar Pembelanjaan Perusahaan, Edisi ketujuh, Penerbit BPFE, Yogyakarta, 2016

Rizal Rizaludin , "Pengaruh Modal Kerja Terhadap Sisa Hasil Usaha",2017

Sudana, I Made. (2015). "Manajemen Keuangan Perusahaan”.Edisi Kedua. Jakarta: Erlangga

Sugiyono. (2016). "Metode Penelitian Kuantitatif Kualitatif Dan R\&B." Bandung: Alfabeta.

Supriyadi dan Fazriani, 2015, "Pengaruh Modal kerja Tehadap Likuiditas dan profitabilitas pada PT. Timah Tbk" 